\title{
Culturally Responsive Teaching through the Lens of Dual Language Education: Intersections and Opportunities
}

\author{
Tammy Oberg De La Garza ${ }^{1, *}$, Alyson L. Lavigne ${ }^{2}$, Shouqing Si ${ }^{2}$ \\ ${ }^{1}$ College of Education, Roosevelt University, United States \\ ${ }^{2}$ College of Education and Human Services, Utah State University, United States \\ Received February 13, 2020; Revised March 18, 2020; Accepted March 28, 2020
}

Copyright $\bigcirc 2020$ by authors, all rights reserved. Authors agree that this article remains permanently open access under the terms of the Creative Commons Attribution License 4.0 International License

\begin{abstract}
Students benefit from culturally responsive teaching (CRT). CRT is central to dual language (DL) education - an additive approach that is effective for educating emergent bilinguals and closing the achievement gap. Students' achievements in DL education models are higher than in any other type of language learning pedagogy - ESL, Bilingual and Monolingual. The purpose of this research was to identify the CRT practices that are employed in DL classrooms; so that teachers in other educational settings (i.e. mainstream, ESL, bilingual) might implement similar practices and improve their effectiveness with diverse students. Using survey responses from Dual Language teachers $(N=151)$, this study examined the intersection of CRT practices and DL teachers self-reported practice. This empirical study reveals that three out of the eight features of Gay's CRT framework were present in DL teachers' practices: validating, multidimensional, and empowering. DL teachers validate students' experience through speaking affirmations, offering texts that represent and reflect students' culture, differentiating instruction, and providing cooperative learning experiences for students. The CRT practices that are multidimensional involve establishing a welcoming and safe climate and including performance assessment to authentically evaluate students' learning. Finally, DL teachers empower their students by offering instruction that facilitates independence in learning. These study findings provide a unique window into DL teacher practice, which can be leveraged by administrators and mainstream teachers to improve the achievement of diverse learners in every classroom.
\end{abstract}

Keywords Culturally Responsive Teaching, Dual Language, Multicultural Education, Diverse Students, Self-Efficacy

\section{Introduction}

How might dual language education models - that by design treat students' linguistic diversity as an asset—provide a rich context for enacting culturally responsive teaching practices? We first begin by exploring the tenets of culturally responsive teaching, followed by the pillars of dual language education. We then consider the intersecting elements of these two frameworks and introduce a research study that we conducted to illuminate how dual language educators' efficacy and practices are situated in this overlapping space.

\subsection{Organizing Frameworks}

\subsubsection{Culturally Responsive Teaching}

Since the 1970s there have been a number of responses to the growing need to be more effective in teaching diverse students. Responses have taken the form of concepts, approaches to teaching, and theoretical frameworks for instruction, including: culturally appropriate [1], culturally congruent [2], culturally responsive [3-5], multicultural education [6,7], culturally responsive teaching [8-10], culturally relevant pedagogy [11-15], and more recently: culturally sustaining [16-18], revitalizing [19], and disruptive pedagogies [20].

Modern approaches to teaching diverse students call for educators to not only respond to students' cultural and linguistic heritages, but also sustain them [18]. Such an approach honors that racial, ethnic, and linguistic identities evolve, and are complex and intersectional. We value this perspective, however, in order for our study to bridge theory, practice, and research, we chose Gay's [10] contributions to culturally responsive teaching (CRT) to inform our research because her work provides both 
theoretical pillars and rich examples of practice.

CRT builds a cultural tie between students and teachers and empowers them to function in multiple cultural settings, contents and systems; effectively providing equity in education without forcing diverse students to operate in mainstream culture or deny their own culture. CRT helps teachers foster "effective, good, responsive, emancipatory, and relevant instruction" [21, p.57] by drawing upon students' lived experiences and cultural backgrounds and communicating a high regard for teaching and learning [21].

Gay $[10, p .36]$ argues that culturally responsive teachers use "the cultural knowledge, prior experiences, frames of reference, and performance styles of ethnically diverse students to make learning encounters more relevant to and effective for them. It teaches to and through the strengths of these students". This also includes teachers' cultural sensitivity and use of cross-cultural communication skills and practices to demonstrate genuine care for students in ways that foster students' cultural competence in their home and school lives [14]. CRT acknowledges culture both as legacies that affect students' dispositions, affect, and approaches to learning, and as worthy content for curriculum.

According to Gay [10], CRT is characterized by eight features:

1. Validating and affirming. Gay $[10$, p. 37] contends that CRT is "validating and affirming" because it incorporates the cultural heritages of students into instruction through multicultural approaches in all subjects, connects students' school experiences to their lived experiences, and strengthens their cultural pride and identity.

2. Comprehensive and inclusive. Culturally responsive teachers "teach the whole child" [10, p.38] intellectually, emotionally, socially, and politically. Teachers not only reinforce high academic achievement, but also strive to maintain students' cultural identity and values through the use of reflective materials and resources.

3. Multidimensional. CRT involves many essential dimensions of education, such as curriculum, learning environment, relationships, instructional methods, and assessment, which "requires tapping into a wide range of cultural knowledge, experiences, contributions, and perspectives" $[10$, p.39].

4. Empowering. CRT emphasizes the importance of empowerment that "translates into academic competence, personal confidence, courage, and the will to act" (Gay, 2018, p. 40). Learners are motivated to set personal goals, achieve academically, and become better human beings.

5. Transformative. Through CRT students confront and challenge cultural inequalities embedded in education. Students become social agents who advocate for social change for equality and social justice.
6. Emancipatory. CRT "releases the intellect of students of color from the constraining manacles of mainstream canons of knowledge and ways of knowing" [10, p.42]. Students become open-minded to learning and are exposed to different versions of truth through authentic knowledge and multiple perspectives, which produces liberating freedom to discover information.

7. Humanistic. CRT encompasses knowledge about self and others. "It is ultimately concerned with the human welfare, dignity, and respect" [10, p.44]. Students gain deeper knowledge of diverse cultures and experiences of both majority and minority groups so that they can be culturally responsive to each other by acknowledging and respecting differences.

8. Normative and ethical. Recognizing that U.S. education is Eurocentric, CRT encourages the continual review of what is "normative" and for whom. Education that reflects everybody's culture should be "both the normal and the right thing to do to incorporate cultural diversity into educative process intended for ethnically, racially, and socially diverse students" [10, p.45].

CRT enhances learning outcomes for all learners [10, 21] - their motivation, attendance [22], and high school graduation rates [10,23]. Howard [24] contends that one benefit of CRT is to close achievement gaps in today's classrooms; Milner [25] emphasizes the advantage of applying CRT to narrow opportunity gaps in American schools. The positive relationship between the implementation of CRT and students' academic achievement and development $[23,26,27]$ may be due to culturally responsive teachers that understand and empathize with students' cultural, language, racial, and socioeconomic backgrounds [25], which enables them to establish a caring environment where "all students feel fully seen, heard, respected, and cared for" [28]. When a safe and caring learning environment is secured, positive classroom relationships flourish. Learners situate themselves as co-constructors and influencers of their own learning [29], resulting in improvements in students' motivation and attendance [20,22].

In sum, teachers who enact CRT affirm the cultural backgrounds of students, and are able to connect instruction to students' funds of knowledge - the culturally developed skills, resources, language, and knowledge that are present in students' homes, families, and communities [30]. When teachers acknowledge students' home languages as assets, students' identities are validated which in turn supports their achievement [31,32]. Language, then, provides an important conduit for considering the use and implementation of CRT.

\subsubsection{Language Instruction Models}

In the U.S., seven models of instruction are employed to 
teach emergent bilinguals (EBs) ${ }^{1}$ who are dominant in a language other than English: Sheltered English Instruction, Structured English Immersion (SEI), English as a Second Language (ESL) Pull-out, ESL Push-in, and three models of Transitional Bilingual Instruction: Early-exit, Late-exit, and Dual Language (DL), one-way or two-way. The goal of Sheltered English Instruction, Structured English Immersion (SEI), and ESL programs is to expose children to English to increase their English proficiency and help them acclimate into American culture [32,33].

One outcome of such English-only approaches is that EBs often feel an academic division with their peers due to their lagging skills in reading and writing [34]. Further, because the language and culture of EBs are negated in English-only classrooms, they experience relational disconnects from their teachers and isolation from the educational experience as a whole [37]. It is no surprise that EBs receiving instruction in such subtractive educational models, fall into the lowest performing academic group and have the highest grade-retention and drop-out rates in the nation [38].

Conversely, EBs in bilingual programs are taught academic language and content in their first language in order to keep up with the students in mainstream classrooms. Early-exit transitional bilingual instruction emphasizes second language acquisition in order to transfer students into English-only classrooms after one to three years. In late-exit transitional bilingual programs, more emphasis is placed on developing students' first language over a five- to seven-year transitional phase [41].

At the far end of the continuum is an additive bilingual program-Dual Language (DL) education. This approach employs students' native (minority) language and English language instruction to support academic fluency in both languages, helping students to embrace their home culture and expand their first language, while successfully operating in mainstream American culture [41]. Three core goals of DL education - bilingualism and biliteracy, academic achievement, and sociocultural competence - [39] largely contribute to the effectiveness and success of DL programs. Classrooms in this five- to twelve-year model are populated by at least one-third English speakers and at least one-third EBs (two-way), or can also be composed of students from the same language and cultural background (one-way).

In the primary grades, the majority of the day is conducted in the students' native (minority or partner) language. Thomas and Collier [40] note that "the rationale for [EBs and first-language English speakers] initially

1 We use the term emergent bilinguals (EBs) instead of English language learners (ELLs) or Limited English proficient students (LEPs) - commonly used terms in the U.S.- to disrupt the discourse and related labels that reproduce a deficit perspective of students who enter school with proficiency in languages other than English [35]. We also recognize that all learners enrolled in DL programs are by default EBs, thus when possible we describe the language backgrounds of students by referring to English-dominant and Other Language-dominant [36]. Finally, we use first and second language as well as minority (partner) and majority language as it refers to programmatic aspects of DL. receiving large amounts of curricular time in the minority language is that society provides a great deal of access to academic English outside of school, and much less for the minority language" (p.14). At the intermediate grades, instruction shifts to a $50 \%$ split and remains at that proportion for the remainder of the DL educational experience, ideally through high school. The objectives of DL education include developing students who are bilingual, biliterate and bicultural; which is a more additive goal than simply learning English. Figure 1 from Oberg De La Garza and Mackinney [41] portrays the seven types of instruction along the subtractive/additive continuum.

DL education is the most effective model of educating ELLs [42]. When EBs engage in DL for at least 6 years they academically and linguistically outperform their peers in all other instructional programs - including those in English-only classrooms [40]. Figure 2 portrays longitudinal data from Thomas and Collier's [40] that demonstrate that (a) additive models of instruction are more effective than subtractive approaches, and (b) students in DL education academically achieve at the highest levels. 


\section{English Language Instruction Program Model Continuum}

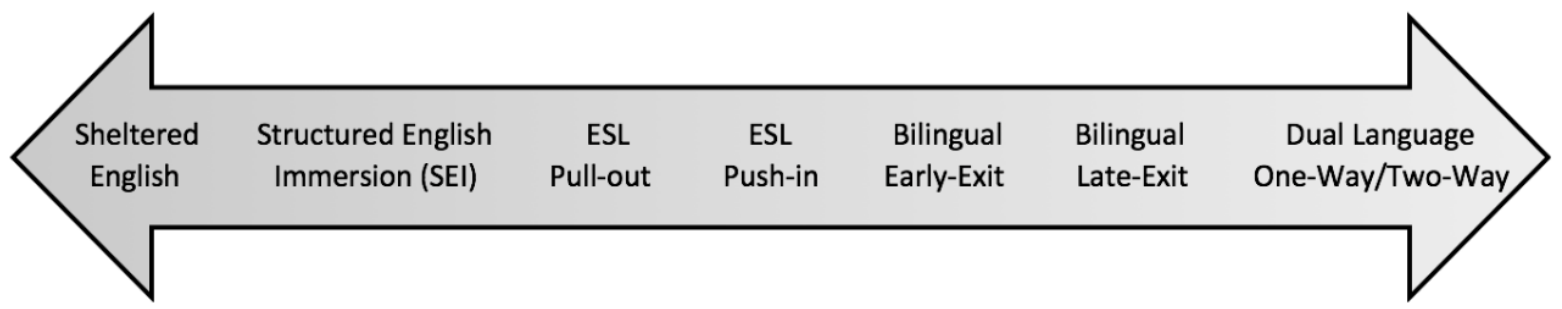

Subtractive

Additive

Figure 1. English Language Instruction Program Model Continuum [41]

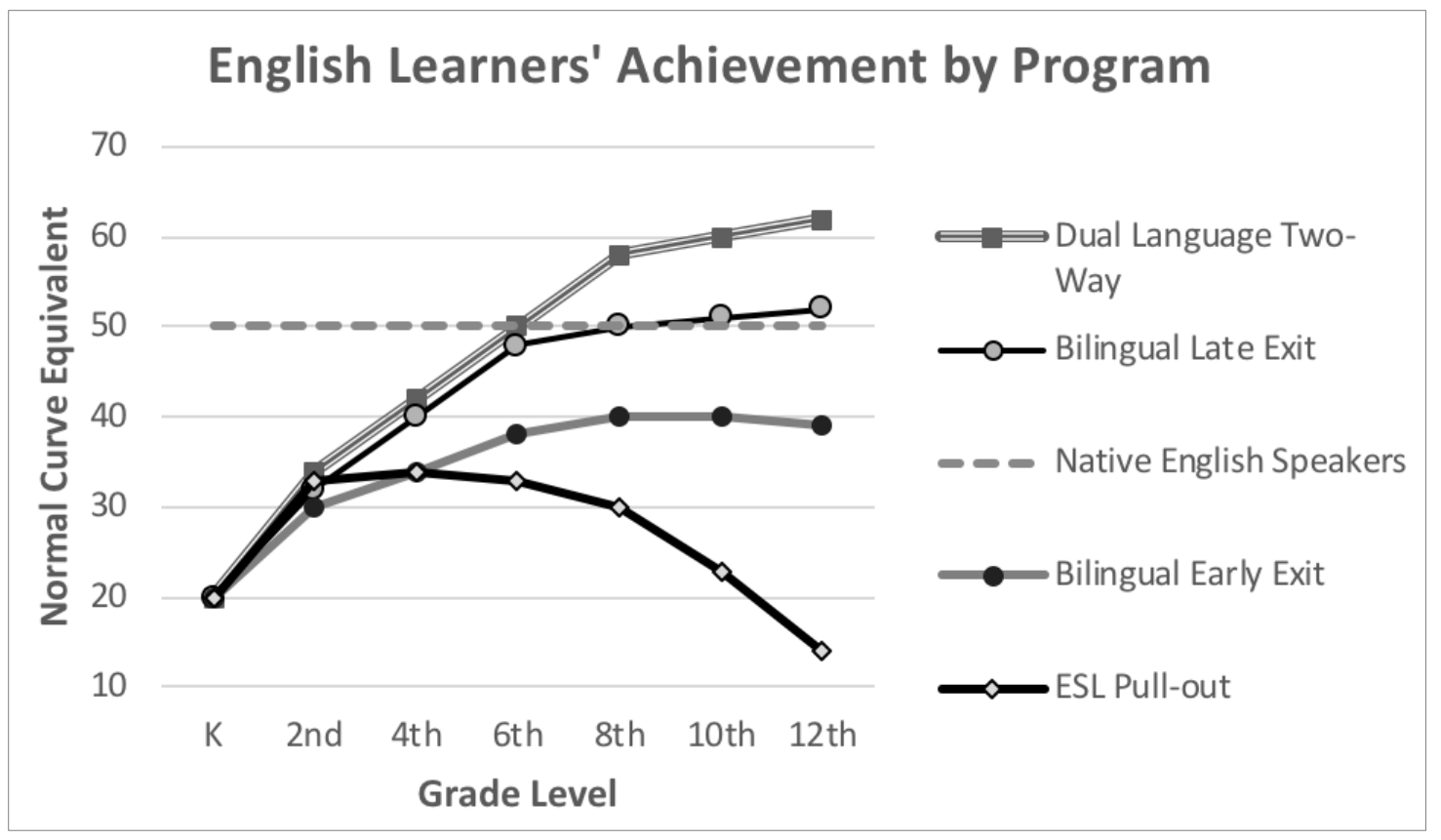

Figure 2. English Learners' Achievement by Program [40] 


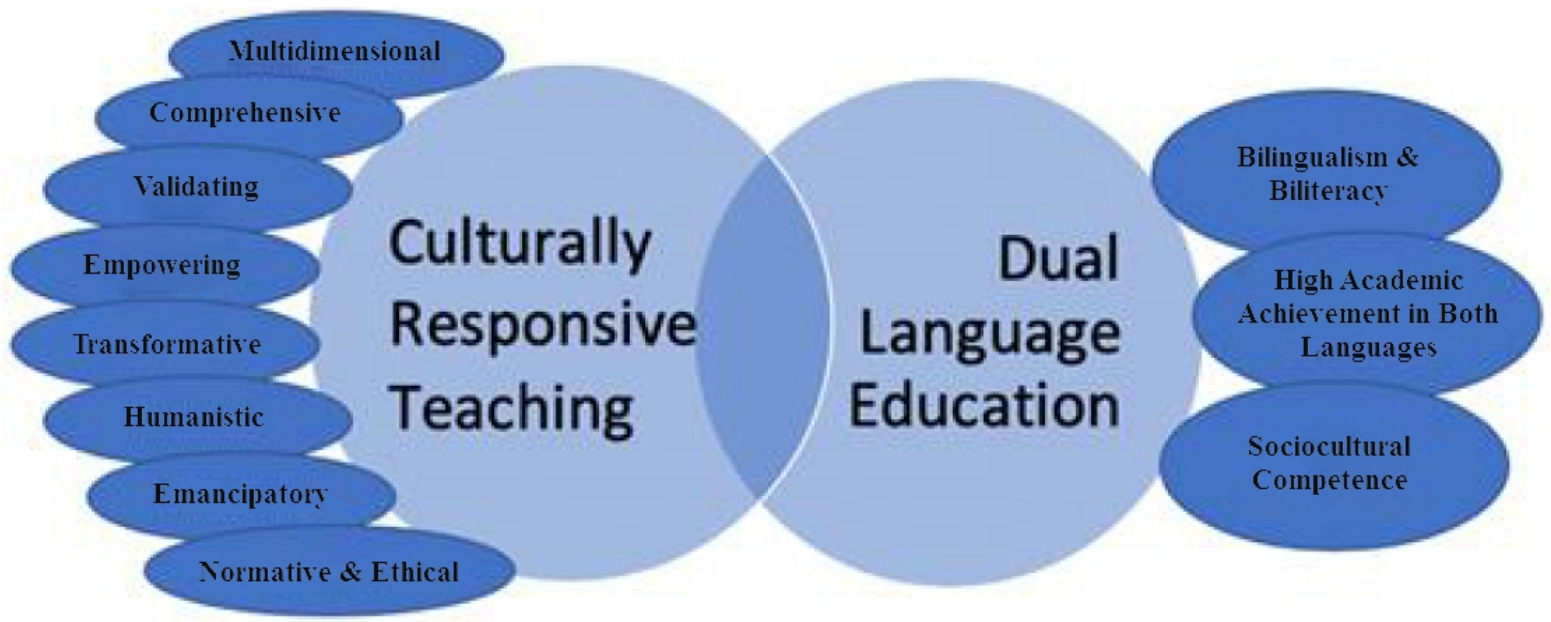

Figure 3. Intersection of Culturally Responsive Teaching \& Dual Language Education

In order to teach in a way that is culturally responsive, teachers must have an understanding of the others' culture and possess the belief that they are capable of successfully implementing CRT [43]. To access the higher levels of academic achievement, students need teachers who are confident in their ability to teach in culturally responsive ways. This might be particularly salient in DL settings where teachers serve a high percentage of EBs who may be culturally and linguistically diverse. DL teachers, therefore, are situated at the important intersection of the eight features of CRT - multidimensional, comprehensive, validating, empowering, transformative, humanistic, emancipatory, and normative and ethical [10] and the three pillars of DL education - bilingualism and biliteracy, high academic achievement in both languages, and sociocultural competence [39]. See Figure 3.

Further, given that students in DL programs achieve at the highest levels, perhaps their teachers also have high levels of self-efficacy in their ability to leverage CRT in the classroom. CRT is an area in which most teachers receive limited preparation [44-46]. However, some teachers of color and teachers who share their students' language backgrounds (who may also be more likely to be employed as DL teachers) may feel particularly efficacious in CRT [47-49,50], with the exception of teaching mathematics and science through a cultural lens [48,51]. This study explores these assumptions and related evidence by examining DL teachers' CRT self-efficacy and the CRT-specific practices that are part of their repertoires.

\section{Methods}

\subsection{Study Context}

This study is part of a larger project the Beliefs of Bilingual Educators (BBE) project, conducted by Alyson Lavigne, Tammy Oberg De La Garza, and Erin Mackinney (IRB Protocol \#9056). The goal of the BBE project was to examine the beliefs and perceptions of effective practice of teachers in various types of bilingual education programs. This larger study consisted of survey data from over 400 bilingual educators across two states. The data reported here represent a subset of data instruments as well as a sub-sample of all participants from the larger BBE project.

\subsection{Participants}

Licensed teachers (full time or part time), whose primary instructional role was in a DL program, with complete survey data were included for analysis in the current study. The final sample consisted of 151 DL teachers. See Table 1. 
Table 1. Participants' Individual and Classroom Characteristics

\begin{tabular}{|c|c|c|}
\hline Variables and associated reponse categories* & $n$ & $\%$ \\
\hline \multicolumn{3}{|l|}{ Individual Characteristics } \\
\hline \multicolumn{3}{|l|}{ Race } \\
\hline American Indian or Alaska Native & 3 & $2.0 \%$ \\
\hline Black or African American & 3 & $2.0 \%$ \\
\hline White & 107 & $70.9 \%$ \\
\hline Other & 26 & $17.2 \%$ \\
\hline Prefer not to answer & 11 & $7.3 \%$ \\
\hline \multicolumn{3}{|l|}{ Ethnicity } \\
\hline No, not of $\mathrm{H}$ ispanic, Latino, or Spanish origin & 28 & $18.5 \%$ \\
\hline \multicolumn{3}{|c|}{ Yes, another Hispanic, Latino, or Spanish origin (e-g., Argentinean, Colombian, } \\
\hline Dominican, Nicaraguan, Salvadoran, Spaniard) & 20 & $13.2 \%$ \\
\hline Yes, Cuban & 1 & $0.7 \%$ \\
\hline Yes, Mexican, Mexican Am., Chicano & 92 & $60.9 \%$ \\
\hline Yes, Puerto Rican & 10 & $6.6 \%$ \\
\hline \multicolumn{3}{|l|}{ Gender } \\
\hline Female & 127 & $84.1 \%$ \\
\hline Make & 22 & $14.6 \%$ \\
\hline Prefer to Self Describe & 1 & $0.7 \%$ \\
\hline \multicolumn{3}{|l|}{ Language Acquisition Background } \\
\hline Monolingual & 4 & $2.6 \%$ \\
\hline Sequential B ilingual (learned 2nd language after 3 years of age) & 112 & $74.2 \%$ \\
\hline Simultaneous Bilingual (leamed two languages from birth) & 34 & $22.5 \%$ \\
\hline \multicolumn{3}{|l|}{ In Bilingual/ESL Education } \\
\hline$<1$ year & 5 & $3.3 \%$ \\
\hline $1-5$ years & 43 & $28.7 \%$ \\
\hline 6-10 years & 41 & $27.3 \%$ \\
\hline $11-15$ years & 25 & $16.7 \%$ \\
\hline$>15$ years & 35 & $23.3 \%$ \\
\hline \multicolumn{3}{|l|}{ In Dual Language Education } \\
\hline$<1$ year & 3 & $2.0 \%$ \\
\hline $1-5$ years & 70 & $46.7 \%$ \\
\hline 6 - 10 years & 45 & $30.0 \%$ \\
\hline $11-15$ years & 14 & $9.3 \%$ \\
\hline$>15$ years & 18 & $12.0 \%$ \\
\hline \multicolumn{3}{|l|}{ Bilingual/ESL Coordinator } \\
\hline Yes & 13 & $8.6 \%$ \\
\hline No & 136 & $90.1 \%$ \\
\hline \multicolumn{3}{|l|}{ Special Education Teacher } \\
\hline Yes & 5 & $3.3 \%$ \\
\hline No & 146 & $96.7 \%$ \\
\hline
\end{tabular}

* Percentages based on total responses.

Participants were almost evenly split between the two DL models-one-: $51 \%(n=77)$ and two-way: $49 \%$ $(n=74)$. A majority of teachers identified as white $(71 \%$; $n=107)$, followed by 'other' race $(17 \% ; n=26)^{2}$. A majority identified as Hispanic, Latino, and Spanish origin $(81.4 \%, n=123)$, with $61 \%$ of the total participant pool identifying as Mexican, Mexican American, Chicano

2 When participants were prompted to specify their race under other, responses included: Hispanic, Latino/a/x, Mestizo, Mexican, Spaniard Taino - African, and White, Black, Native American. origin $(61 \%, n=92)$.

\subsection{Procedures and Instruments}

In Fall of 2017, via an online survey, teachers completed a screener followed by a demographic survey that consisted of a series of questions about their own individual characteristics as well as the characteristics of the students they teach.

Teachers' efficacy as it pertains to culturally responsive pedagogy was measured using the Culturally Responsive 
Teaching Self-Efficacy Scale (CRTSE)[44]. In this 40-item scale, teachers rated their confidence in their ability to engage in culturally responsive teaching practices (e.g., Use my students' cultural background to help make learning meaningful) by indicating a degree of confidence $(0=$ no confidence at all $; 100=$ completely confident $)$. Item responses are summed to generate a total score. A higher score indicates a higher level of CRT self-efficacy. Internal reliability for the CRSTE (Cronbach's alpha $=.96$ ) was established by Siwatu [44] using a sample of preservice teachers $(N=275)$ in the Midwest who were predominantly female $(73 \%)$ and white $(93 \%)$ and that indicated a mean CRT self-efficacy score of $3361.89(S D=342.03$, Range: 2270-3970).

Teachers were also randomly assigned to rate to what extent they feel particular practices under the areas of: planning, instruction, professional responsibilities, classroom climate, physical classroom environment, or assessment are critical in order for them to be effective in their current role. They were then prompted to answer the following question: As you reflect back on the list of practices, are there any practices that you feel are critical in order for teachers to be effective that are not listed above? The purpose of this question was to tap into teacher-generated practices and expertise.

\subsection{Analysis}

Descriptive statistics were calculated for teachers' responses to the CRTSE. Then, raw data from DL educators' responses to the above question were collected from each area of practice: planning (29 responses), instruction (23 responses), professional responsibilities (11 responses), classroom climate (7 responses), physical classroom environment (10 responses), assessment (5 responses). Responses were then coded using the eight components of Gay's [10] CRT framework. Each component represented a single thematic code that was annotated with a definition and one or more classroom examples. Using this deductive analysis method, we examined all the data from the lens of these preordained theoretical themes. The data were carefully analyzed and then either explicitly or implicitly categorized into one of the eight features of Gay's CRT framework. To be specific, one datum read, "I would add social and or emotional needs, especially for my immigrant population under these uncertain times," and it became an explicit fit under the validating theme as it directly contains keywords "social and or emotional needs" that appeared in the definition for the theme.

\section{Results and Discussion}

Below we provide a summary of results that are then integrated into a discussion that focuses primarily on implications and opportunities for practice for DL teachers and other teachers who serve diverse learners in their classrooms.

\subsection{CRT Self-Efficacy}

DL teachers who participated in this study boasted high levels of CRT self-efficacy as represented by CRTSE item level means that ranged from 72.66 to 95.34 (on a 100-point scale). On average, teachers reported the highest efficacy in building a sense of trust in their students $(M=$ 95.34; $S D=8.26$ ) and developing a personal relationship with their students $(M=95.07 ; S D=11.25)$. Teachers were the least efficacious about: designing a lesson that shows how other cultural groups have made use of mathematics $(M=72.66 ; S D=26.29)$, and teaching students about their cultures' contributions to science $(M=74.62 ; S D=24.01)$. See Table 2. 
Table 2. Descriptive Statistics for the Culturally Responsive Teacher Efficacy Scale [44]

\begin{tabular}{|c|c|c|c|}
\hline Item & $N$ & $M$ & $S D$ \\
\hline \multicolumn{4}{|l|}{ I am able to... } \\
\hline 1. Adapt instruction to meet the needs of my students. & 151 & 89.58 & 11.84 \\
\hline 2. Obtain information about my students' academic strengths. & 151 & 91.33 & 11.74 \\
\hline 3. Determine whether my students like to work alone or in a group. & 151 & 92.03 & 14.34 \\
\hline 4. Determine whether my students feel comfortable competing with other students. & 151 & 88.77 & 15.01 \\
\hline $\begin{array}{l}\text { 5. Identify ways that the school culture (e-g., values, norms, and practices) is different } \\
\text { students' home culture. }\end{array}$ & 151 & 84.89 & 17.68 \\
\hline $\begin{array}{l}\text { 6. Implement strategies to minimize the effects of the mismatch between my student } \\
\text { culture and the school culture. }\end{array}$ & 151 & 83.18 & 17.68 \\
\hline 7. Assess student leaming using various types of assessments. & 151 & 91.02 & 13.21 \\
\hline 8. Obtain information about my students" home life. & 151 & 86.09 & 16.32 \\
\hline 9. Build a sense of trust in my students. & 151 & 95.34 & 8.26 \\
\hline 10. Establish positive home-school relations. & 151 & 91.62 & 13.10 \\
\hline 11. Use a variety of teaching methods. & 151 & 91.62 & 11.87 \\
\hline $\begin{array}{l}\text { 12. Develop a community of leamers when my class consists of students from diverse } \\
\text { backgrounds. }\end{array}$ & 151 & 89.85 & 14.82 \\
\hline 13. Use my students' cultural background to help make leaming meaningful. & 151 & 91.34 & 14.40 \\
\hline $\begin{array}{l}\text { 14. Use my students' prior knowledge to help them make sense of new information. } \\
\text { 15. Identify ways in which how students communicate at home may differ from the sc }\end{array}$ & 151 & 92.02 & 12.74 \\
\hline 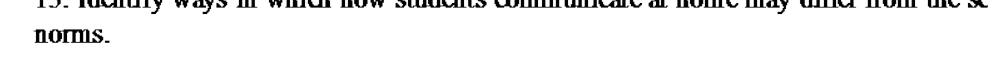 & 151 & 85.01 & 15.16 \\
\hline 16. Obtain information about my students' cultural background. & 151 & 88.62 & 15.18 \\
\hline 17. Teach students about their cultures' contributions to science & 151 & 74.62 & 24.01 \\
\hline 18. Greet English Language Leamers with a phrase in their native language. & 151 & 93.92 & 15.97 \\
\hline 19. Design a classroom environment using displays that reflects a variety of cultures. & 151 & 86.28 & 17.80 \\
\hline 20. Develop a personal redationship with my students. & 151 & 95.07 & 11.25 \\
\hline 21. Obtain information about my students' academic weaknesses. & 151 & 93.07 & 11.34 \\
\hline
\end{tabular}

Table 2 (continued)

\begin{tabular}{|c|c|c|c|}
\hline Item & $N$ & $M$ & $S D$ \\
\hline \multicolumn{4}{|l|}{ I am able to... } \\
\hline \multicolumn{4}{|l|}{ 22. Praise English Language Learners for their accomplishments using a phrase in their native } \\
\hline language. & 151 & 93.11 & 16.22 \\
\hline 23. Identify ways that standardized tests may be biased towards linguistically diverse students. & 151 & 83.13 & 19.38 \\
\hline 24. Communicate with parents regarding their child's educational progress. & 151 & 94.13 & 10.43 \\
\hline 25. Structure parent-teacher conferences so that the meeting is not intimidating for parents. & 151 & 93.34 & 10.61 \\
\hline 26. Help students to develop positive relationships with their classmates. & 151 & 92.36 & 12.19 \\
\hline 27. Revise instructional material to include a better representation of cultural groups. & 151 & 82.80 & 18.01 \\
\hline $\begin{array}{l}\text { 28. Critically examine the curriculum to determine whether it reinforces negative cultural } \\
\text { stereotypes. }\end{array}$ & 151 & 82.40 & 18.29 \\
\hline 29. Design a lesson that shows how other cultural groups have made use of mathematics. & 151 & 72.66 & 26.29 \\
\hline 30. Model classroom tasks to enhance English Language Learners' understanding. & 151 & 92.82 & 12.95 \\
\hline $\begin{array}{l}\text { 31. Communicate with the parents of English Language Leamers regarding their child's } \\
\text { achievement. }\end{array}$ & 151 & 95.00 & 9.90 \\
\hline 32. Help students feel like important members of the dassroom. & 151 & 94.62 & 12.36 \\
\hline 33. Identify ways that standardized tests may be biased towards culturally diverse students. & 151 & 82.40 & 19.80 \\
\hline 34. Use a leaming preference inventory to gather data about how my students like to lean. & 151 & 83.64 & 20.44 \\
\hline 35. Use examples that are familiar to students from diverse cultural backgrounds. & 151 & 88.19 & 15.66 \\
\hline 36. Explain new concepts using examples that are taken from my students' everyday lives. & 151 & 91.40 & 13.54 \\
\hline 37. Obtain information regarding my students' academic interests. & 151 & 90.34 & 14.19 \\
\hline 38. Use the interests of my students to make learning meaningful for them. & 151 & 91.76 & 13.81 \\
\hline 39. Implement cooperative learning activities for those students who like to work in groups. & 151 & 92.36 & 13.41 \\
\hline 40. Design instruction that matches my students' developmental needs. & 151 & 91.23 & 12.92 \\
\hline
\end{tabular}




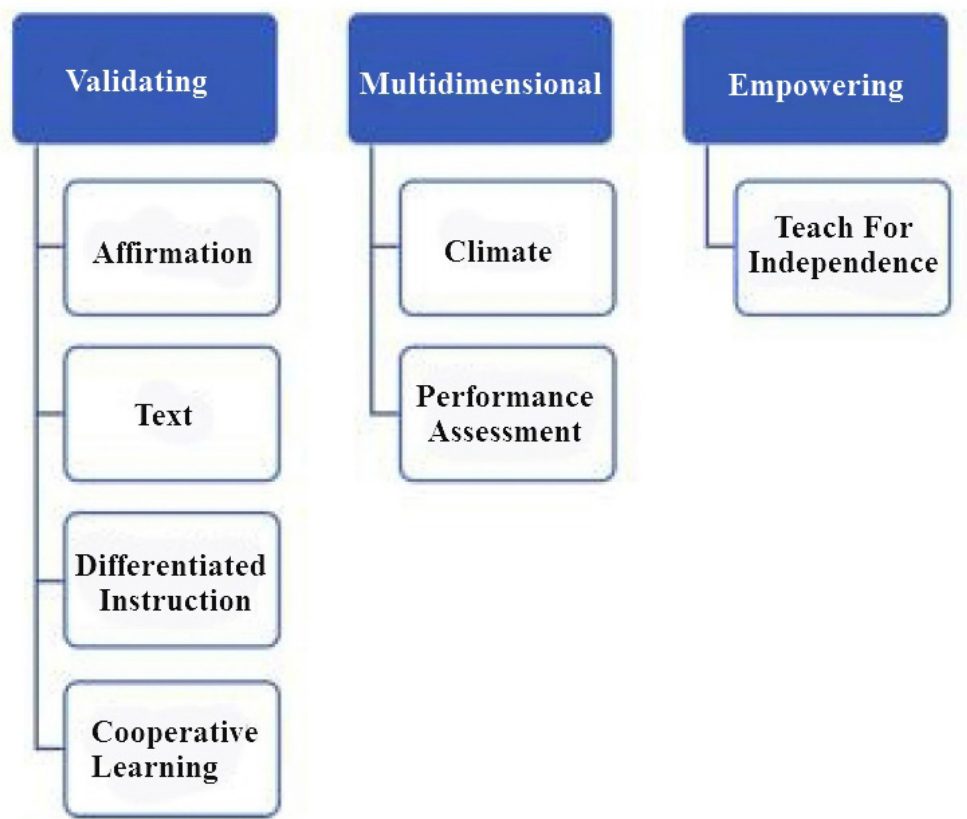

Figure 4. CRT Features in DL Teachers' Practice

\subsection{CRT Practices}

Three out of the eight features of Gay's CRT framework emerged from DL teachers' practices: validating, multidimensional, and empowering. Within each of these, the practices were organized into separate sub-categories. The validating feature included a variety of practices related to text, differentiated instruction, cooperative learning, and affirmation. The multidimensional feature was categorized into climate and performance assessment. The empowering feature demonstrated instructional practices that were taught for independence. The validating feature contained the most practice responses, the multidimensional feature had half as many, and the empowering feature had the lowest number of responses of the three. Figure 4 demonstrates the organization of features and categories.

\subsubsection{Validating}

CRT that is validating reinforces students' cultural pride and identity by connecting school experiences to their lived experiences, traditions and language. DL teachers in this study provided a valuable list of specific practices that validate students' experiences. The data on these responses were analyzed and can be organized into four separate categories: affirmation, text, differentiated instruction, and cooperative learning (bolded in the text below). What follows is a discussion of each, direct quotes from teachers' responses, and implications for classroom practice for all teachers of diverse students.

Affirmation is the cornerstone of CRT. It is not about inflating a student's self-esteem, rather it is the acknowledgement that the teacher is aware of and appreciates the diverse qualities of the classroom members
- race, language, experience, gender, skill level, etc. Validating affirmation recognizes and addresses inequities, while giving voice to students' experiences.

In this study, DL teachers emphasized their role in supporting and demonstrating an understanding of students' culture, background, and needs. Not only understanding, but the DL teachers' words, actions and attitudes actively respect their students' cultures. Additionally, the practice of DL classrooms involves fluent mastery of both English and the partner language, and the teachers affirm and acknowledge students' intents when communicating in either of the languages - no matter the difficulty or number of errors. In responding to something a student has mispronounced or erred in word selection, rather than explicitly correcting the student, 'No, that is not how you say it,' a DL teacher might respond with the grammatically correct iteration of what the student was attempting to say. These subtle practices occur numerous times throughout every school day, and though single instances may not have an impact, the collective affect lays the groundwork for every decision about resources, instructional activities, curriculum and assessment.

DL teachers make deliberate choices about the text that students encounter in the classroom, textbooks, classroom libraries and read alouds. One DL teacher indicated the use of news articles written in students' heritage language to explore current events and social issues. This teacher felt that it was a really good tool for students to practice their language skills and expand their academic vocabulary. Another teacher selected "a variety of high interest texts in both languages" for students to read and discuss. A third teacher shared the importance of providing "additional texts in the students' language to support their needs." The value in providing texts in students' first or home 
language(s) goes beyond expanding their skills, vocabulary and language - it strengthens students' understanding of the context of their culture; and in the two-way DL classroom, it gives native-English speakers the opportunity to explore a foreign culture.

When considering texts, teachers of diverse learners should include picture books and grade-appropriate novels in the classroom in the language of their non-English, heritage speakers. In addition to bilingual books, the classroom library should also include books in English that portray the "other's" experience, characters or context. Books that emphasize the role that various cultures play in the historical progression of and modern-day understandings of science in mathematics may be particularly important to emphasize. Even the DL teachers in this study - who might be the best positioned to do and know this work-feel the least efficacious in these areas of CRT. For teachers whose diverse students are dominant Spanish or Portuguese speakers, there is a valuable website, The American Association of Teachers of Spanish and Portuguese which includes links, summaries, and reviews of more than 400 websites in various languages (https://www.aatsp.org/page/cr_sites_spanish/

Classroom-Resources-Websites-of-Interest---Spanish.htm

2. In addition to online dictionaries, newspapers, and magazines, websites include cultural information, virtual museum visits, radio programs, classroom activities and materials and teaching tools such as graphic organizers and maps.

Differentiated Instruction involves tailoring instruction to meet individual students' needs. Teachers may differentiate content, process, products, the learning environment, assessments and/or flexible grouping when shaping instruction to match students' levels, experiences, languages or prior knowledge. In this study, ten teachers reported differentiated instruction and/or gave specific examples of their practice.

Three teachers described the use of visuals, realia, or "students' own artifacts from home to make connections," reinforced meaning, and strengthened understanding. One teacher reported using a wide variety of videos to reinforce concepts. Another educator utilizes student-created anchor charts with pictures or students' drawings. An example of a picture anchor chart is below (Figure 5).

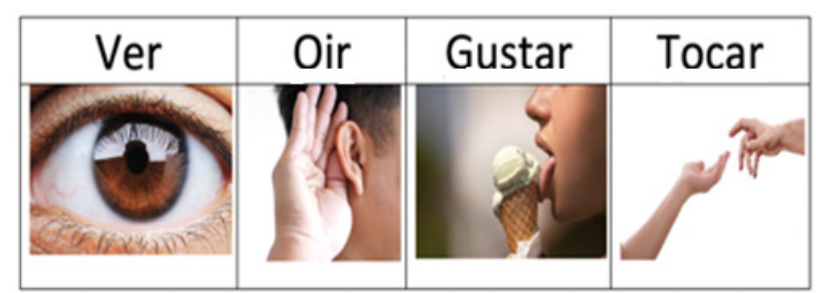

Figure 5. Picture Anchor Chart in Spanish

Other approaches to differentiated instruction involve the instructional activities themselves. One teacher reported using "movement to represent concepts." This references Total Physical Response (TPR), a language teaching method that creates a link between a new word and a physical movement (i.e. teacher says the word "jump" while jumping). Teachers in the study also incorporated teachers' modeling of word pronunciation, journal writing, and students' presentations as ways of tailoring instruction to foster learning in all students.

Mainstream classroom teachers whose student body includes EBs as well as dominant-English speakers might increase the impact of their lessons by differentiating instruction to meet the needs of their diverse learners. Develop assignments that emphasize students' personal heritage such as interviews, research projects, or oral histories of family members. Provide service learning projects that directly benefit the community. Highlight role models who come from backgrounds similar to those of your students. One great resource is a website (www.lathisms.org) created in 2016 by Latino scholars, and uses podcasts and biographies to showcase the contributions of Latinx and Hispanic mathematicians during Hispanic Heritage Month. The website is open year-round, and with 30 different Latinx role models each year, currently features more than 100 Latinx role models in the mathematics and science arena. Another powerful web-based resource is www.BeyondCurie.com, "a design project that highlights badass women in science, technology, engineering + mathematics." Teachers can gain information on various women, but also download and print engaging posters featuring different role models.

There is copious research supporting the use of cooperative learning groups to enhance students' achievement [52-55]. In addition to improved academic performance, engaging students in cooperative learning promotes critical thinking, teamwork, self-esteem, interpersonal relationships, better attitudes toward school and peers, and recognition of themselves as learners [56]. The benefits of this value-added learning approach positively impact diverse students' bodies.

DL teachers in this study utilized cooperative learning in various ways across the curriculum. The greatest reported practice among participants was peer-teaching. Peer teaching or tutoring is a strategy that pairs students to practice academic skills and deeply understand content. There are three different types of peer tutoring: reciprocal (bi-directional), class-wide, and cross-age.

In reciprocal peer tutoring, both students take on the role of tutor, while the other student is the learner. The roles can switch with different skills, content areas, time or units. Class-wide peer tutoring involves the entire class being divided into pairs. The tutor uses task cards for question prompts, error corrections, and to keep the tutoring focused on the objective. Cross-age peer tutoring takes place when an older student is paired with a younger child. In DL settings, peer tutoring can be particularly pertinent to building students' language, especially when classrooms 
have a significant number of dominant language models in each language so that these students can be equally distributed to students with less proficiency in peer tutoring arrangements.

One DL teacher's cooperative learning example worth noting is writing workshop. This method of writing instruction teaches students to write for a variety of audiences and purposes, while receiving feedback from peers and coaching from the teacher. Integrating cooperative learning into writing has proven a more effective way of developing students' writing skills than traditional methods [57-58]. Other cooperative learning strategies reported by DL teachers include the use of games, role-play, and inviting students to bring and discuss artifacts from home.

\subsubsection{Multidimensional}

The multidimensional feature was categorized into climate and performance assessment (as noted in bold below).

Socio-political consciousness $[10,14]$ was evident in DL teachers' attention to the political climate, including the importance of addressing "social and or emotional needs, especially for my immigrant population under these uncertain times." Another teacher noted, "I strive to build positive relationships of culture." Additionally, DL teachers acknowledged the importance of recognizing power when navigating languages in the school.

In addition to attending to climate on a large scale, DL teachers in this study also noted their emphasis on individual students' needs. Including shy students in conversations and activities was something that was important to one savvy DL educator. Teachers also tended to the physical layout of the classroom to achieve this goal, as one teacher noted: "Students sit at tables rather than desks in order to promote conversations. DL teachers also recognized the need to advocate for individual students as well as the whole class.

Just as CRT instruction and resources are important to diverse learners, DL teachers in this study reported a reliance on authentic and culturally responsive performance assessments to measure learning. To effectively measure the learning progress of DL students, their language proficiency must be measured in both languages (majority and target). Rather than using a single, standardized measure for high-stakes evaluation, DL programs use multiple measures. Researchers have long, voiced concerns related to the use of standardized measures of DL English mastery [59]. They recommend a combination of standardized tests, curriculum-embedded assessments, narrative language samples, and observation of children's language in authentic settings [60-62]. To improve the validity of test results, practitioners are encouraged to make accommodations on large-scale assessments for bilinguals such as providing: simplified English in test directions, design, and question prompts;
English dictionaries/glossaries; the language of tests in the language of instruction, and extended time, or use of untimed tests [63-65]. Additionally, test data should be collected over a period of time and administered by faculty and staff whose cultural attitudes not only recognize diversity, but are aligned with sustaining it also.

\subsubsection{Empowering}

The final features of instructional routines, self-reported by DL teachers, were empowering practices that illustrated teaching for independence. Study findings of empowering CRT-specific practices underscored how DL teachers illustrate care for their students by preparing them to independently operate and leverage their language culture [8]. Educators communicated the importance of teaching students how to learn in addition to what to learn. DL teachers explicitly teach reading and vocabulary strategies to students so they can employ these tools during independent reading activities in either language. They also teach students how to locate resources, "for example word-to-word, bilingual dictionaries, ask a peer and language apps."

Additionally, DL teachers empowered students through metalinguistic awareness - thinking about and making conscious choices about different language use and vocabulary. This included creating a classroom where: "objects are labeled in two languages to start increasing recognition between similarities in language." Fostering students' metalinguistic awareness empowers them to analyze, think and talk about language independent of the concrete meaning of each word [66]. One DL teacher made a point of teaching students how to identify "cognates and word roots [to] help them connect the two languages."

Metalinguistic awareness significantly impacts reading comprehension and achievement [67-69]. Examples of metalinguistic instruction include: exposing students to multiple meanings of words, developing cognate recognition, introducing figurative language, playing with words and language (riddles, jokes, rhymes), and making inferences. This also included creating a classroom where: "objects are labeled in two languages to start increasing recognition between similarities in language." One DL teacher made a point of teaching students how to identify "cognates [to] help them connect the two languages."

Translanguaging, another instructional approach that overlaps with metalinguistic awareness, is the deliberate mixing of linguistic features from different languages to facilitate communication ${ }^{3}$. Learners are thinking about and making word choices to best express themselves, without the constraints of separating the languages. This can be a powerful tool for learning. Spanglish (the use of Spanish mixed with English), is a form a translanguaging where an

3 Translanguaging was likely not noted by teachers in the open-ended statements because it was already listed as practice in the instruments provided to teachers. However, teachers who participated in the study generally agreed or strongly agreed that "showing grace toward students" use of translanguaging in the classroom" in an effective practice for EBs. 
individual uses their full linguistic repertoire for communication and sensemaking. This practice is often stigmatized and perceived as evidence of errors in learning. What is often thought of as "errors," in actuality represents a natural linguistic process, an innovative and hybrid use of resources, and a display of the complex understanding students hold of multiple languages within even just a single phrase [70]. Together, with the other features of CRT, DL teachers demonstrate self-efficacy in a spectrum of practices that directly impact the motivation, attitude and achievement of bilingual learners.

\section{Conclusions}

CRT connects diverse students' personal experiences to classroom practices and curriculum; helping them excel in education. DL education is the most impactful model of language instruction for EBs - those who are dominant-English speakers as well as those dominant in other languages. In this study, we examined the intersection of CRT and the related efficacy and practices of DL teachers to illuminate methods and areas of opportunity that can benefit diverse students in other instructional models (including mainstream English classrooms).

DL teachers were the most efficacious in building relationships with their students, but they were the least efficacious in highlighting the cultural contributions of various communities to mathematics and science. Given that teachers have expressed the need for support in these areas in other studies [48,51], together these findings point to an opportunity for schools to increase their effectiveness in this aspect of CRT and underscores the need for more resources that address these particular areas. DL teachers were able to identify effective practices in three out of eight CRT features, as defined by Gay [8]: validating, multidimensional, and empowering. DL teachers enacted a wide variety of validating practices which affirmed students' cultures/experiences, included a variation of texts - in perspective and language, utilized differentiated instruction, and incorporated cooperative learning throughout. The reported multidimensional practices that DL teachers reported were more limited; emphasizing classroom climate and performance assessment. The empowering feature of teaching was limited to teaching for independence, but included a deep commitment to developing students' ability to learn and function independently.

The additive strategies and practices unique to DL settings can be tailored to fit the needs of all classrooms that serve diverse youth. DL education, is the vehicle in which teachers delve more deeply in CRT, effectively disrupting normative conceptions of schools to sustain, not just respond to culture. Teachers of diverse students in all settings - bilingual, ESL, mainstream English - can capitalize on CRT found in additive, DL approaches by engaging students in validating, multidimensional, and empowering instructional practices discussed above and can emphasize cultural contributions to science and mathematics while doing so.

\subsection{Need for Future Work}

We chose Geneva Gay's theoretical approach because it helped us illuminate how teachers' practices might fall under these themes and inadvertently, the results generated additional questions. For example, we wonder: Can CRT be conceptualized on a developmental spectrum? Do some elements of CRT develop earlier than others? To what extent do school-level policies, practice, and climate foster or restrict the enactment of CRT? Our research was initially informed by CRT, therefore our methodology did not particularly target sustaining approaches to this instructional framework which is a limitation of the study at hand. We believe, then, that subsequent research that includes sustenance from its inception may illuminate other ways that teachers seek to understand and also value students and the multiple cultural communities in which they identify [18].

\section{Acknowledgements}

We are very grateful to the educators who agreed to participate in this study. We are acutely aware that without their participation, this work is not possible. Further, we would like to thank Erin Mackinney for her work in co-conceptualizing the larger study, the Beliefs of Bilingual Educators project.

\section{REFERENCES}

[1] K. Au, C. Jordan. Teaching reading to Hawaiian children: Finding a culturally appropriate solution, In H. Trueba, G. Guthrie, K. Au (Eds.), Culture and the bilingual classroom: Classroom ethnography, 139-152, Newbury House, Rowley, MA, 1981.

[2] G. Mohatt, F. Erickson. Cultural differences in teaching styles in an Odawa school: A sociolinguistic approach, In $\mathrm{H}$. Trueba, G. Guthrie, \& K. Au (Eds.), Culture and the bilingual classroom: Classroom ethnography, 105-119), Newbury House, Rowley, MA, 1981.

[3] C. B. Cazden, E. L. Leggett. Culturally responsive education: A response to remedies, In H. Trueba, G. Guthrie and K. Au (Eds.) Culture and the Bilingual Classroom: Studies in classroom ethnography, 69-86, Newbury House, Rowley, MA, 1981.

[4] J. Cummins. Empowering minority students: A framework for intervention, Harvard Educational Review, Vol.56, No.1, 
18-36, 1986.https://doi.org/10.17763/haer.56.1.b32723446 1607787

[5] J. Cummins, J. Bilingual education and English immersion: The Ramirez report in theoretical perspective, Bilingual Research Journal, Vol.16 No.1-2, 91104, 1993. https://doi.org/10.1080/15235882.1992.10162630

[6] J. A. Banks. An introduction to multicultural education. Allyn \& Bacon, Boston, 1994.

[7] J. B. Banks, C. A. M. Banks, (Eds.). Handbook of research on multicultural education. Macmillan, New York, 1995.

[8] G. Gay. Culturally responsive teaching: Theory, research, and practice, 2 nd ed., Teachers College Record, New York, 2010.

[9] G. Gay. Teaching to and through cultural diversity. Curriculum Inquiry, Vol.43, No.1, 48-70, 2013. https://doi. org/10.1111/curi.12002

[10] G. Gay. Culturally responsive teaching: Theory, research, and practice, 3rd ed., Teachers College Press, New York, 2018.

[11] G. Ladson-Billings. The dreamkeepers: Successful teachers of African-American children, Jossey-Bass, San Francisco, 1994.

[12] G. Ladson-Billings. But that's just good teaching! The case for culturally relevant pedagogy, Theory into Practice, Vol.34, No.3, 159-165, 1995a. https://doi.org/10.1080/004 05849509543675

[13] G. Ladson-Billings. Toward a theory of culturally relevant teaching, American Educational Research Journal, Vol.32, No.3, 465-491, 1995b.https://doi.org/10.3102/0002831203 2003465

[14] G. Ladson-Billings. Yes, but how do we do it? Practicing culturally relevant pedagogy, In J. Landsman \& C. W. Lewis (Eds.), White teachers/diverse classrooms: A guide to building inclusive schools, promoting high expectations, and eliminating racism, 29-42, Stylus, Sterling, VA, 2006. https://doi.org/10.1080/00131940701634718

[15] G. Ladson-Billings. Culturally relevant pedagogy 2.0: A.k.a. the remix, Harvard Educational Review, Vol.84, No.1, 74- 84, 2014. https://doi.org/10.17763/haer.84.1.p2rj13148 5484751

[16] D. Paris. Culturally sustaining pedagogy: A needed change in stance, terminology, and practice, Educational Researcher, Vol.41, No.3, 93-97, 2012.https://doi.org/10.3 102/0013189X12441244

[17] D. Paris, H. S. Alim. What are we seeking to sustain through culturally sustaining pedagogy? A loving critique forward, Harvard Educational Review, Vol.84, No.1, 85-100, 2014. https://doi.org/10.17763/haer.84.1.9821873k2ht16m77

[18] D. Paris, H. S. Alim. Culturally sustaining pedagogies: Teaching and learning for justice in a changing world, Teachers College Press, New York, 2017.

[19] T. McCarty, T. Lee. Critical culturally sustaining/revitalizing pedagogy and Indigenous education sovereignty, Harvard Educational Review, Vol.84, No.1, 101-124, 2014.https://doi.org/10.17763/haer.84.1.q83746n $15 \mathrm{pj} 34216$
[20] T. San Pedro. Abby as ally: An argument for culturally disruptive pedagogy. American Educational Research Journal, Vol.55, No.6, 1193-1232, 2018. https://doi.org/10. $3102 / 0002831218773488$

[21] H. Milner, H. Cunningham, L. O'Connor, E. Kestenberg. These kids are out of control: Why we just reimagine "classroom management" for equity, Corwin, New York, 2018.

[22] T. S. Dee, E. K. Penner. The casual effects of cultural relevance: Evidence from an ethnic studies curriculum, American Educational Research Journal, Vol.54, No.1, 127-166, 2017. https://doi.org/10.3102/0002831216677002

[23] N. L. Cabrera, N. L., J. F. Milem, O. Jaquette, R. W. Marx. Missing the (student achievement) forest for all the (political) trees: Empiricism and the Mexican American studies controversy in Tucson, American Educational Research Journal, Vol.51, No.6, 1084-1118. https://doi.org $/ 10.3102 / 0002831214553705$

[24] T. C. Howard. Why race and culture matter in schools: Closing the achievement gap in American classrooms, Teachers College Press, New York, 2010.

[25] R. Milner. Start where you are but don't stay there: Understanding diversity, opportunity gaps, and teaching in today's classrooms. Harvard Education Press, Cambridge, MA, 2010.

[26] C. Garcia, H. Chun. Culturally responsive teaching an teacher expectations for Latino middle school students. Journal of Latina/o Psychology, Vol.4, No.3, 173-187, 2016 https://doi.org/10.1037/lat0000061

[27] R. Powell, S. C. Cantrell, V. Malo-Juvera, P. K. Correll Operationalizing Culturally Responsive Instruction: Preliminary findings of CRIOP research, Teachers Colleg Record, Vol.118, No.1, 1-46, 2016

[28] R. Milner, H. Cunningham, L. O'Connor, E. Kestenberg. These kids are out of control: Why we just reimagine "classroom management" for equity, Corwin, New York, 2019.

[29] G. Ladson-Billings. The dreamkeepers: Successful teachers of African American children. John Wiley \& Sons, San Francisco, CA, 2009.

[30] N. González, L. C. Moll, C. Amanti. Funds of knowledge: Theorizing practices in households, communities, and classrooms, Lawrence Erlbaum Associates Inc., Mahwah, NJ, 2005. https://doi.org/10.4324/9781410613462

[31] O. García, L. Wei. Translanguaging. Language, bilingualism and education, Palgrave Macmillan, London, UK:, 2014 https://doi.org/10.1057/9781137385765

[32] F. López, E. McEneaney. State implementation of language acquisition policies and reading achievement among Hispanic students, Educational Policy, Vol.26, No. 3, 418-464, 2012. https://doi.org/10.1177/0895904811417581

[33] M. Adams, K. M. Jones. Unmasking the myths of structured English immersion: Why we still need bilingual educators, native language instruction and incorporation of home culture, Radical Teacher, Vol.75, 16-21, 2006.

[34] F. Chang, G. Crawford, D. Early, D. Bryant, C. Howes, M. Burchinal, R. Pinata. Spanish-speaking children's social 
and language development in pre-kindergarten classrooms, Early Education and Development, Vol.18, 243-269, 2007. https://doi.org/10.1080/10409280701282959

[35] O. García. Emergent, bilinguals and TESOL: What's in a name?, TESOL quarterly: A journal for teachers of English to speakers of other languages and standard English as a second dialect, Vol.43, No.2, 322-326, 2009. https://doi.org /10.1002/j.1545-7249.2009.tb00172.x

[36] S. Braden. Emblems of identity: A typology of uses of Spanish by diverse students in an English-medium science classroom. Paper at the annual meeting of the American Association for Applied Linguistics (AAAL), Chicago, IL, 2018

[37] A. Valenzuela. Subtractive schooling, State University of New York Press, New York, 1999.

[38] W. P. Thomas, V. P. Collier. A national study of school effectiveness for language minority students' long-term academic achievement, Santa Cruz, CA, and Washington, DC: Center for Research and Education, Diversity and Excellence, 2002.

[39] E. R. Howard, J. Sugarman, D. Christian, K. J. Lindholm-Leary, D. Rogers. Guiding principles for dual language education, 3rd ed., Center for Applied Linguistics, Washington, DC, 2017.

[40] W. P. Thomas, V. P. Collier. Dual language education for a transformed world, Fuente, Albuquerque, NM, 2012.

[41] T. Oberg De La Garza, E. Mackinney, E. Teaching English in the United States: Looking back and moving forward towards a brighter future, Studies in English Language Teaching, Vol.6, No.2, 86-96, 2018. https://doi.org/10.221 $58 /$ selt.v6n2p86

[42] K. J. Lindholm-Leary, G. Borsato, G. Academic achievement, In F. Genesee, K. Lindholm-Leary, W. Saunders, D. Christian (Eds.), Educating English language learners: A synthesis of research evidence, 176-222, Cambridge University Press, New York, 2006.

[43] A. Bandura. Social foundations of thought and action: A social cognitive theory, Prentice- Hall, Inc., Englewood Cliffs, NJ, 1986.

[44] K. O. Siwatu. Preservice teachers ' culturally responsive teaching self-efficacy and outcome expectancy beliefs, Teaching and Teacher Education, Vol. 23, 1086-1101, 2007. https://doi.org/10.1016/j.tate.2006.07.011

[45] K. O. Siwatu. Preservice teachers' culturally responsive teaching self-efficacy-forming experiences: A mixed methods study, The Journal of Educational Research, Vol. 104, No.5, 360-369, 2011. https://doi.org/10.1080/0022067 1.2010 .487081

[46] C. A. Warren. Empathy, teacher dispositions, and preparation for culturally responsive pedagogy, Journal of Teacher Education, Vol.69, No.2, 169-183, 2018. https://d oi.org/10.1177/0022487117712487

[47] S. Chu, S. Garcia. Culturally responsive teaching efficacy beliefs of in-service special education teachers. Remedial and Special Education, Vol.35, No.4, 218-232, 2014. https://doi.org/10.1177/0741932513520511

[48] K. J. Debnam, E. T. Pas, J. Bottiani, A. H. Cash, C. P.
Bradshaw. An examination of the association between observed and self-reported culturally proficient teaching practices. Psychology in the Schools, Vol.52, No.6, 533-548, 2015. https://doi.org/10.1002/pits.21845

[49] R. T. Knowles A. M. Hawkman. Anti-racist quantitative research: Developing, validating, and implementing racialized teaching efficacy and racial fragility scales, The Urban Review, 2019. https://doi.org/10.1007/s11256-019-00526-1

[50] O. Paneque, P. Barbetta. A study of teacher efficacy of special education teachers of English language learners with disabilities. Bilingual Research Journal, Vol.30, 171-193, 2006. https://doi.org/10.1080/15235882.2006.10162871

[51] J. A. Freire, V. E. Valdez, V. E. Dual language teachers' stated barriers to implementation of culturally relevant pedagogy. Bilingual Research Journal, Vol.40, No.1, 55-69, 2017. https://doi.org/10.1080/15235882.2016.1272504

[52] D. Johnson, R. Johnson. Cooperation and competition: Theory and research, Interaction Book Company, Edina, MN, 1989.

[53] R. Slavin. Cooperative learning: Theory, research, and practice. Englewood Cliffs, NJ: Prentice-Hall, 1990.

[54] R. Slavin. Synthesis of research on cooperative learning. Educational Leadership, Vol. 48, 71-82, 1991.

[55] R. Slavin. Making cooperative learning powerful. Educational Leadership, Vol. 72, No.2, 22-26, 2014.

[56] P. Gándara, P. The potential and promise of Latino students, American Educator, Vol.41, No.1, 4-11, 2017.

[57] D. Graves. Writing: Teachers and children at work, Heinemann Educational Books, Exeter, NH, 1983.

[58] L. Calkins. A guide to the writing workshop: Primary grades, Heinemann Books, Exeter, NH, 2017.

[59] National Academies of Sciences, Engineering, \& Medicine, (2017). Promising and effective practices in assessment of dual language learners' and English learners educational progress. In Takanishi, R \& Le Menestrel, S (Eds.) Promoting the Educational Success of Children and Youth Learning English: Promising Futures. Washington, DC: The National Academics Press. https://doi.org/10.17226/24677

[60] D. August, T. Shanahan. Developing Literacy in Second-Language Learners: Report of the National Literacy Panel on Language Minority Children and Youth Executive Summary, Lawrence Erlbaum Associates, Mahwah, NJ, 2006.

[61] V. F. Gutiérrez-Clellen, M. A. Restrepo, G. Simon-Cereijido. Evaluating the discriminant accuracy of a grammatical measure with Spanish-speaking children, Journal of Speech, Language and Hearing Research, Vol.49, 1209-1223, 2006. https://doi.org/10.1044/1092-4388(2006/087)

[62] M. Neill. Assessment of ELL Students under NCLB: Problems and Solutions, 2005. Available: http://www.fairt est.org/sites/default/files/NCLB_assessing_bilingual_stude nts_0.pdf.

[63] E. Burr, E. Haas, E., K. Ferriere. Identifying and supporting 
English learner students with learning disabilities: Key issues in the literature and state practice, REL 2015-086, Regional Educational Laboratory West, Washington, DC, 2015.

[64] M. J. Kieffer, M. Rivera, D. J. Francis. Practical Guidelines for the Education of English Language Learners: Research-Based Recommendations for the Use of Accommodations in Large-Scale Assessments. Portsmouth, NH: RMC Research Corporation, Center on Instruction, 2012.

[65] S. Lane, B. Leventhal. Psychometric challenges in assessing English language learners and students with disabilities, Review of Research in Education, Vol.39, No.1, 165-214, 2015. https://doi.org/10.3102/0091732X14556073

[66] B. Shulman, N. Capone. Language development: Foundations, processes and clinical applications. Jones \& Bartlett Learning, Burlington, MA, 2010.

[67] K. Cain. Syntactic awareness and reading ability: Is there any evidence for a special relationship? Applied Psycholinguistics, Vol.28, 679-694, 2007. https://doi.org/1 $0.1017 / \mathrm{S} 0142716407070361$

[68] M. Zipke. The role of metalinguistic awareness in the reading comprehension of sixth and seventh graders. Reading Psychology, Vol.28, No.4, 375-396, 2007. https:// doi.org/10.1080/02702710701260615

[69] M. Zipke, L. E. Ehri, H. Cairns. Using semantic ambiguity instruction to improve third graders' metalinguistic awareness and reading comprehension: An experimental study. Reading Research Quarterly, Vol.44, No.3, 300-321, 2009. https://doi.org/10.1598/RRQ.44.3.4

[70] M. Bucholtz, D. I. Casillas, J. S. Lee. Language and culture as sustenance, In D. Paris and H. S. Alim (Eds.), Culturally sustaining pedagogies: Teaching and learning for justice in a changing world, 43-60. Teachers College Press, New York, 2017. 